九州大学学術情報リポジトリ

Kyushu University Institutional Repository

\title{
Development of a Prediction Model of Fuel Moisture Changes in a Deciduous Forest of Yeongdong Region in Korea
}

Lee, Si-Young

Professional Graduate School of Disaster Prevention, Kangwon National University

Kwon, Chun-Geun

Professional Graduate School of Disaster Prevention, Kangwon National University

Ko, Dongwook W.

Department of Forest Environmental Systems, Kookmin University

Park, Gwan-Soo

Department of Forest Resources, Chungnam National University

他

https://doi.org/10.5109/1434375

出版情報：九州大学大学院農学研究院紀要. 59 (1)，pp.19-24，2014-02-28. Faculty of Agriculture， Kyushu University

バージョン :

権利関係 : 


\title{
Development of a Prediction Model of Fuel Moisture Changes in a Deciduous Forest of Yeongdong Region in Korea
}

\author{
Si-Young LEE ${ }^{1}$, Chun-Geun Kwon ${ }^{1}$, Dongwook W. Ko ${ }^{2}$, \\ Gwan-Soo PARK ${ }^{3}$ and Shoji OHGA*
}

\author{
Laboratory of Forest Resources Management, Division of Forest Environmental \\ Sciences, Department of Agro-Environmental Sciences, Faculty of Agriculture, \\ Kyushu University, Fukuoka 811-2415, Japan \\ (Received September 24, 2013 and accepted November 11, 2013)
}

\begin{abstract}
Understanding how fuel moisture changes after a rainfall is important to predict forest fire risk, and knowing such change in advance can greatly assist in fire risk monitoring. To better understand the fuel moisture dynamics after a rainfall, we investigated how fuel moisture level changes across four different fuel layers (fall leaves, humus, top soil layer ( $<5 \mathrm{~cm}$ depth), and lower soil layer $(5-10 \mathrm{~cm} \mathrm{depth))} \mathrm{under}$ three different stand density levels (high, medium and low) after a significant rainfall event ( $>5 \mathrm{~mm}$ ) during spring season. We measured variables including effective humidity, solar irradiation, wind speed, and days after rainfall. These variables were incorporated into developing a fuel moisture prediction regression model.

Variables were measured daily for 6 days after a rainfall, for a total of 4 rainfall events in the spring of 2008 for model development, and one event in the spring of 2009 for model validation. Results show that in a low density stand, fuel moisture of the fallen leaves layer reached a dangerously dry level of $17 \%$ only after 3 days since rainfall, while at the medium and high density stands, fuel moisture level remained at 19-20\% after 6 days since rainfall. Fuel moisture at the humus level was highest among all fuel layers, and remained at greater than 57\% even after 6 days since rainfall. Top and lower soil layers both showed small to no changes in fuel moisture content throughout the sampling period. The prediction regression model showed a reasonable performance $\left(R^{2}=0.56-0.90, p-\right.$ value $\left.<0.001\right)$ and validated well against an independent set of measurements.
\end{abstract}

Key words: forest fire, fuel moisture, forest density, prediction model

\section{INTRODUCTION}

Forest fire in Korea predominantly occurs during spring and fall seasons. Spring forest fire, in particular, consists approximately $60 \%$ of all fire events for a given year (East coast forest fire area scrutiny report I, 2000). Yeongdong region in Korea is especially well known for its high susceptibility to forest fires. From 1975 to 2010 , there were 57 fire events that was larger than 100 ha, and $44 \%$ of them occurred in the Yeongdong region. Such concentration of fire events in this specific region is partly attributed to the Foehn wind resulting from the dominant westeries, which transforms into hot, dry and strong winds as they cross over the Taebaek mountain range. Dry and strong wind combined with the dense and pinedominant forest stand provide an ideal condition for large forest fires in this area (Korea Forest Service, 2010).

Forest fuel moisture is an important factor that affects the initiation, intensity, and speed of spread of fire events. For example, high fuel moisture content lowers forest fire probability, while dry fuel can promote

\footnotetext{
Professional Graduate School of Disaster Prevention, Kangwon National University, Samcheok-Si, Gangwon-Do 245-711, Republic of Korea

2 Department of Forest Environmental Systems, Kookmin University, Seongbuk-Gu, Seoul, Korea, 136-702, Republic of Korea

Department of Forest Resources, Chungnam National University, Daejeon-Si 305-764, Republic of Korea

* Corresponding Author (E-mail: ohga@forest.kyushu-u.ac.jp)
}

fire probability (Kang et al., 2002). Therefore, fuel moisture is an important factor for fire management and risk assessment, and therefore it is important to investigate factors that affect forest fuel moisture content and characteristics, such as air temperature, humidity, irradiation, wind velocity, and precipitation.

There are numerous studies that estimated the moisture content of flammable fuel and link its contribution to fire risk (Fosberg, 1977). One example is the National Fire Danger Rating System (NFDRS), which was developed in the late 1970s. NFDRS was originally based on a forest floor fuel moisture estimating method by utilizing a fuel moisture stick made of ponderosa pine (Deeming et al., 1977). Dead fuel on forest floor greatly contributes to potential fire risks, but fuel with greater moisture content requires higher energy level for successful ignition events (Fons, 1946; Xanthopoulos and Wakimoto, 1993). It is known that fuel moisture content depends on the amount and structure of the existing fuel, such as the ratio of live and dead biomass, compactness, porosity, particle size, air temperature, relative humidity, and precipitation (Brown, 1970).

Yamashita (1988) showed that fuel starts to dry up from the forest surface immediately after a rainfall, and if large amount of fuel is present the dry-up process will be delayed by several hours in the interior of the bulk of fuel. In addition, strong irradiation and high wind speed will accelerate fuel dry-up. Where there is less fuel accumulation, the influence of rainfall will quickly appear and moisture content will increase rapidly. The speed of fuel 
dry-up will depend on irradiation, wind velocity, air temperature, relative humidity, and bulk density of the fuel materials (Yamashita, 1983).

In Korea, previous studies analyzed fire risk based on fuel level as characterized by tree species and age class, meteorological conditions within and outside of the forest stand, and fuel moisture level (Jung et al., 1989). In a forest stand in Gwangreung area of central Korea, fuel moisture stick method and meteorological data was utilized to develop fire risk index, which was then incorporated into a fire risk forecast system (Lee et al., 1997). Kwon (2009) analyzed the relationship between fire risk and forest fuel moisture content in pine stands of Donghae and Samchuk area of Kangwon province of Korea, and Lee et al. (2010) developed a fuel moisture prediction model based on meteorological data and forest fuel moisture change data (Kwon 2009; Lee et al., 2010).

However, such models are limited by our poor understanding on the relationship between fire risk and the dynamic moisture content of various fuel materials immediately following a rainfall.

In this study, our objectives were to (1) measure and analyze the changes in fuel moisture level of fallen leaves, humus, and two soil layers following a rainfall event in stands with different densities, and (2) develop and test a fuel moisture change prediction model considering the aforementioned variables.

\section{MATERIALS AND METHODS}

\section{Study site and sample collection}

The study site was located in deciduous forest stands at Samchuk region of Kangwon province in Korea. Data collection was carried out during the spring season of 2008 and 2009. The study sites were classified into low, medium and high density stands, where fuel moisture content change was measured after rainfall events (Tanskanen et al., 2005) (Table 1). We measured the variables after a rainfall exceeding $5 \mathrm{~mm}$ of precipitation (Stock, Alexander et al., 1987), and daily sampling continued for 6 days after the day of rainfall. Total of 4 rainfall events (precipitation ranging from $5.5 \mathrm{~mm}$ to $44 \mathrm{~mm}$ ) were sampled in 2009 (Table 2). We excluded the rainfall events less than $5 \mathrm{~mm}$ since fuel moisture did not show sufficient change (Kang et al., 2002).

The size of sampling plots was $10 \mathrm{~m}$ by $10 \mathrm{~m}$, in which three sub-plots were established to collect fallen leaves, humus and soil top and bottom layer $(0-5 \mathrm{~cm}, 5-10 \mathrm{~cm})$. The samples were collected at 10am each day, weighed at site, and then were sealed in a plastic bag and transported to the lab for further analysis. At the time of sample collection, we measured air temperature, relative humidity, and wind velocity (Kestrel 4000), and solar irradiation (INS DX-200).

\section{Analysis}

2.1 Fuel moisture change

Samples of fallen leaves, humus and two soil layers

Table 1. Study Stand and Site Characteristics

\begin{tabular}{|c|c|c|c|c|c|c|c|c|c|c|c|c|c|}
\hline \multirow{2}{*}{ Stand } & \multicolumn{5}{|c|}{ Stand investigation } & \multicolumn{5}{|c|}{ Site investigation } & \multicolumn{3}{|c|}{$\begin{array}{l}\text { Fallen leaves and humus } \\
\text { layer thickness }(\mathrm{cm})\end{array}$} \\
\hline & Species & $\begin{array}{l}\text { Average } \\
\text { Height } \\
\text { (m) }\end{array}$ & $\begin{array}{l}\text { Average } \\
\text { DBH } \\
(\mathrm{cm})\end{array}$ & $\begin{array}{c}\text { Degree } \\
\text { of } \\
\text { closure } \\
(\%)\end{array}$ & $\begin{array}{l}\text { Trees } \\
\text { (ha) }\end{array}$ & $\begin{array}{l}\text { Altitude } \\
\text { (m) }\end{array}$ & $\begin{array}{l}\text { Direc } \\
\text {-tion }\end{array}$ & $\begin{array}{l}\text { Survey } \\
\text { location }\end{array}$ & $\begin{array}{l}\text { Average } \\
\text { slope } \\
\left(^{\circ}\right)\end{array}$ & GPS & $\begin{array}{l}\text { Fallen } \\
\text { leaves } \\
\text { layer }\end{array}$ & $\begin{array}{l}\text { Humus } \\
\text { layer }\end{array}$ & Total \\
\hline Loose & $\begin{array}{l}\text { Quercus } \\
\text { dentata }\end{array}$ & 1.7 & 5.3 & 20 & 500 & 27 & $\mathrm{~S} 20 \mathrm{E}$ & bottom & $13^{\circ}$ & $\begin{array}{l}\mathrm{N} 37^{\circ} 26^{\prime} 08.9^{\prime \prime} \\
\mathrm{E} 129^{\circ} \\
05^{\prime} 31.7^{\prime \prime}\end{array}$ & 1.0 & 1.8 & 2.8 \\
\hline Medium & $\begin{array}{l}\text { Quercus } \\
\text { variabilis }\end{array}$ & 6.7 & 11.3 & 60 & 1700 & 38 & S30E & bottom & $11^{\circ}$ & $\begin{array}{l}\mathrm{N} 37^{\circ} 25^{\prime} 26.0^{\prime \prime} \\
\mathrm{E} 129^{\circ} \\
06^{\prime} 32.3^{\prime \prime}\end{array}$ & 2.1 & 2.8 & 4.9 \\
\hline Dense & $\begin{array}{l}\text { Quercus } \\
\text { variabilis }\end{array}$ & 7.2 & 12.2 & 70 & 2000 & 40 & S20W & bottom & $9^{\circ}$ & $\begin{array}{l}\mathrm{N} 37^{\circ} 25^{\prime} 25.2^{\prime \prime} \\
\mathrm{E} 129^{\circ} \\
06^{\prime} 27.7^{\prime \prime}\end{array}$ & 2.2 & 3.0 & 5.2 \\
\hline
\end{tabular}

Table 2. Survey period details

\begin{tabular}{lllc}
\hline Investigation & \multicolumn{1}{c}{$\begin{array}{c}\text { Duration of } \\
\text { rainfall }\end{array}$} & Survey period & $\begin{array}{c}\text { Accumulated } \\
\text { rainfall }\end{array}$ \\
\hline First investigation & '08 March 22 24 & '08 March 25 March 29 & $44.0 \mathrm{~mm}$ \\
Second investigation & '08 March 30 & '08 March 31 April 5 & $10.0 \mathrm{~mm}$ \\
Third investigation & '08 April 17 & '08 April 18 April 23 & $5.5 \mathrm{~mm}$ \\
Fourth investigation & '08 May 12 13 & '08 May 14 May 19 & $25.6 \mathrm{~mm}$ \\
\hline
\end{tabular}


were oven-dried (105 degrees Celcius, 24 hours) (Anderson, Schuette et al., 1978) and then weighed to estimate fuel moisture content (FMC) so we can estimate the changing fuel moisture level across various fuel layers after the rainfall event. FMC is calculated as:

$F M C(\%)=\left(\frac{W_{W}-W_{d}}{W_{d}}\right) \times 100$ .equation 1

Where FMC is fuel moisture content (\%), $\mathrm{W}_{\mathrm{w}}$ is weight before oven-dry, and $\mathrm{W}_{\mathrm{d}}$ is dry weight.

\subsection{Development and validation of fuel moisture change prediction model}

A regression model for estimating fuel moisture change after a rainfall event was developed (SPSS) (Song et al., 2007). Dependent variable was the fuel moisture level for each of the 6 days after the rainfall events, and independent variables were solar irradiation, wind velocity, effective humidity and stand density (low, medium, and high), and days-since-rainfall (Song et al., 2007). After preliminary analysis, solar irradiation was excluded from further analysis since its influence was negligible. The basic regression model is:

$\hat{Y}=b_{0}+b_{1} D 1 X 4$ equation 2

Where $\mathrm{Y}$ (hat) is the estimated FMC, X4 is a dummy variable to represent three levels of stand density. Therefore the final regression model used in this study was:

$\hat{Y}=b_{0}+b_{1} D 1 X 4+D 2 X 4$ equation 3

To validate our model, we measured the same variables following the same sampling protocols after a rainfall event during the 2009 spring season.

\section{RESULTS AND DISCUSSION}

\section{Fuel moisture change after rainfall event}

\subsection{Comparison of stand density}

Moisture content of fallen leaves, humus, top soil layer, and lower soil layer showed that stands with high density generally showed greater fuel moisture compared to stands with lower density (Fig. 1, 2, 3, 4). Fuel moisture of fallen leaves at the high density stand was higher by $6-20 \%$ and $13-34 \%$ than that of the medium density stand and the low density stand, respectively.

In high and medium density stands, fuel moisture content was still relatively high at 19-20\% after 6 days since rainfall. At the low density stand, however, fuel moisture rapidly dropped to $17 \%$ on the $3^{\text {rd }}$ day. Considering that fuel moisture level lower than $20 \%$ significantly increases flammability and thus fire risk (Pyne 1984; Forest Land Fire Research Group 1984), the results suggest that stand density can strongly influence how fire risk changes after rainfall events. This result is also comparable to other studies based on deciduous stands, where fuel moisture content of fallen leaves dropped to 13-17\% after 4 days since rainfall event (Lee, 1994; Lee

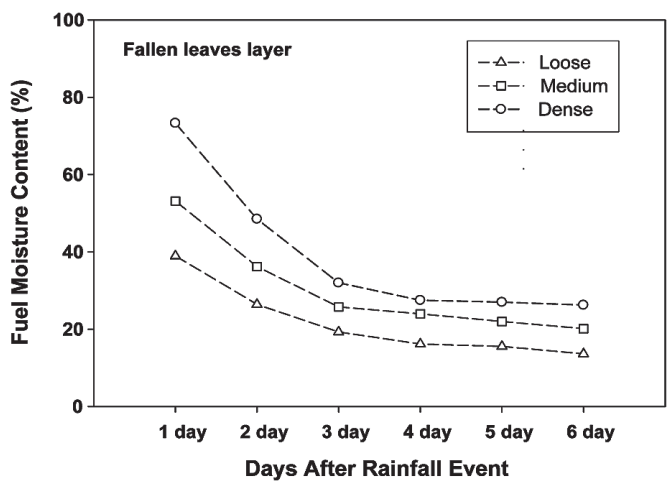

Fig. 1. Fuel moisture content changes of fallen leaves layer.

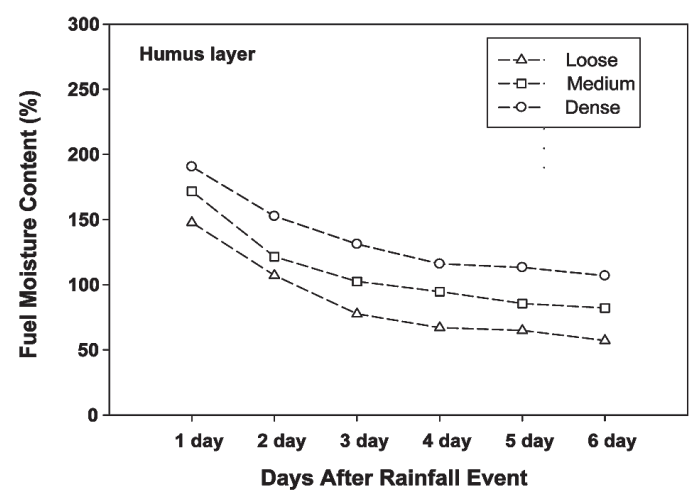

Fig. 2. Fuel moisture content changes of humus layer.

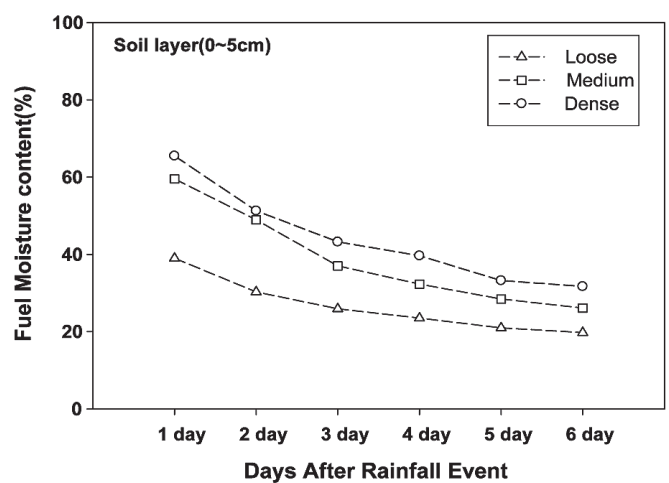

Fig. 3. Fuel moisture content changes of soil layer $(0 \sim 5 \mathrm{~cm})$.

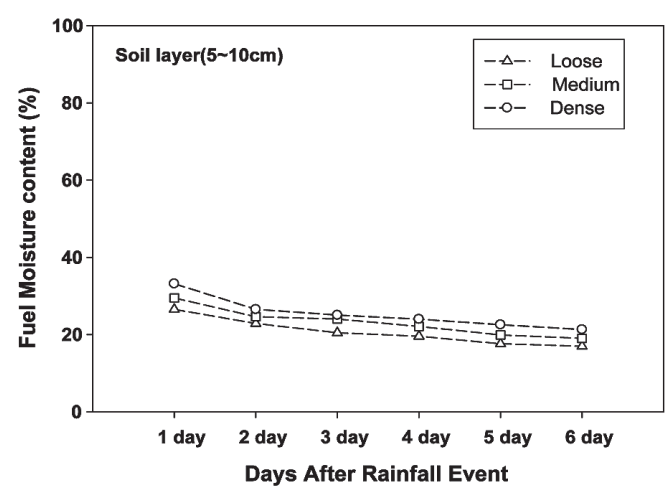

Fig. 4. Fuel moisture content changes of soil layer $(5 \sim 10 \mathrm{~cm})$. 
et al., 2010). Also, fuel moisture changed much rapidly at sites with low fuel accumulation. There are several feasible explanations for these changes. Open structure of low density stands may allow greater amount of solar irradiation to reach the forest floor that warm up and dry the fuel, and more wind can pass through the forest floor resulting in faster fuel desiccation. Thin fuel layers may respond more readily to such drying conditions.

Fuel moisture content of the humus layer was higher in dense stands by $3-7 \%$ and $43-54 \%$ compared to the medium and low density stands, respectively (Fig. 2). Humus fuel moisture was consistently high in all stand density levels immediately after rainfall, which was sustained at 57-106\% even after 6 days. This suggests that flammability of humus layer may be relatively low in any of the conditions considered in this study.

Fuel moisture content at top soil layer was highest at dense sites by $3-7 \%$ and $12-36 \%$ compared to the medium and low density stands (Fig. 6). Soil moisture level was high even after 6 days since rainfall, showing a range of $20-31 \%$. At the lower soil layer, fuel moisture range was $17-33 \%$, which did not differ among stand density level nor did it show significant change throughout the sampling period. This implies that soil layer down to $5 \mathrm{~cm}$ from the surface is sensitive to meteorological conditions in the forest stand, at least during a short period of time (e.g., several days).

\subsection{Comparison of fuel layers}

At low density stands, fuel moisture showed a range of $13-38 \%$ at the fallen leaves layer, $57-147 \%$ at the humus layer, 19-39\% at the top soil layer, and 16-26\% at the lower soil layer (Fig. 5, 6, 7). Fuel moisture content at the humus layer was the highest, which was 44-109\% higher compared to fallen leaves layer. Immediately after a rainfall, fuel layer started to dry from the surface. When there was a large amount of accumulated fuel, the dry-up time was delayed by several hours to a few days. This is probably due to the humus layer being protected by the fallen leaves layer from elements that can promote the drying process, such as open air, relative humidity, solar irradiation, and wind. It is also possible that some of the moisture from the soil layers below the humus layer may have moved up.

At the medium density stands, the highest fuel mois-

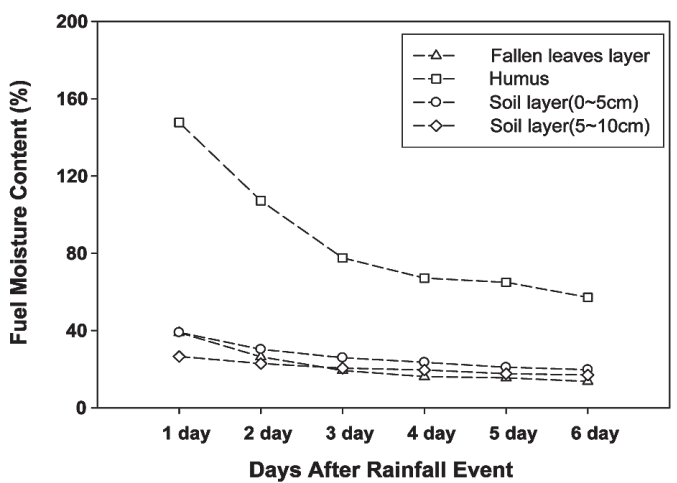

Fig. 5. Fuel moisture content changes of loose stand.

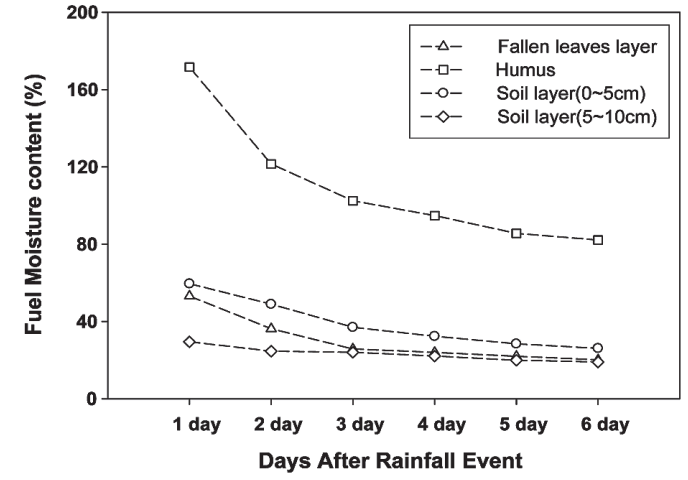

Fig. 6. Fuel moisture content changes of medium stand.

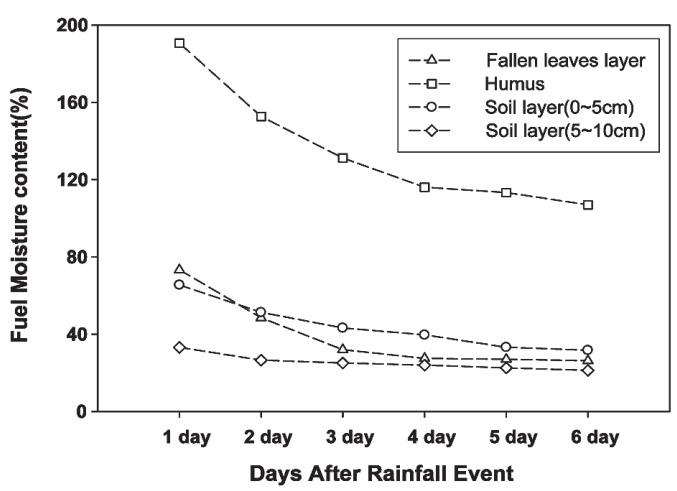

Fig. 7. Fuel moisture content changes of dense stand.

ture level was found at the humus layer (82-171\%), followed by fallen leaves (20-53\%), top soil layer (26-59\%), and lower soil layer (19-29\%) (Fig. 6). The order of fuel moisture level was identical to the high density stands, showing the highest level at the humus layer (106$190 \%)$, followed by fallen leaves (26-73\%), top soil layer (31-65\%), and lower soil layer (21-33\%) (Fig. 7). Results indicate that humus layer in low density stands were generally drier than the rest of the stands. There is a distinct lag effect on fuel moisture change in response to time since rainfall events. Changes in fuel moisture level were most immediate on the layers closest to the surface.

\section{Fuel moisture prediction model}

We developed a regression model with fuel moisture over time as dependent variable and effective humidity $(\mathrm{EH})$, wind speed, cumulative solar irradiation (ALUX), and time-since-rainfall (ED) as independent variables (Table 3, 4). Correlation analysis between fuel moisture change and various meteorological variables and stand density levels indicated that fuel moisture at all fuel layers had high correlation with ALUX, EH and ED, but low correlation with stand density levels. The regression model was significant ( $p$-value $<0.001$ ) and showed good fit with the data (R-square value $=0.908,0.804,0.867$, 0.560 for fall leaves, humus, top soil and lower soil layers, respectively). 
Table 3. Correlations analysis between fuel moisture content and relevant factors

\begin{tabular}{|c|c|c|c|c|c|c|c|}
\hline \multicolumn{2}{|c|}{ Fallen leaves layer } & \multicolumn{2}{|c|}{ Humus layer } & \multicolumn{2}{|c|}{ Soil layer $(0 \sim 5 \mathrm{~cm})$} & \multicolumn{2}{|c|}{ Soil layer $(5 \sim 10 \mathrm{~cm})$} \\
\hline $\begin{array}{c}\text { Pearson } \\
\text { Correlation }\end{array}$ & FMC & $\begin{array}{c}\text { Pearson } \\
\text { Correlation }\end{array}$ & FMC & $\begin{array}{c}\text { Pearson } \\
\text { Correlation }\end{array}$ & FMC & $\begin{array}{c}\text { Pearson } \\
\text { Correlation }\end{array}$ & FMC \\
\hline $\log 10$ (ALUX) & -.724 & $\log 10$ (ALUX) & -.797 & $\log 10$ (ALUX) & -.850 & $\log 10$ (ALUX) & -.711 \\
\hline $\log 10(\mathrm{EH})$ & .747 & $\log 10(\mathrm{EH})$ & .623 & $\log 10(\mathrm{EH})$ & .453 & $\log 10(\mathrm{EH})$ & .442 \\
\hline $\log 10(\mathrm{ED})$ & -.765 & $\log 10(\mathrm{ED})$ & -.690 & $\log 10(\mathrm{ED})$ & -.611 & $\log 10(\mathrm{ED})$ & -.589 \\
\hline $\mathrm{L}$ & -.419 & $\mathrm{~L}$ & -.423 & $\mathrm{~L}$ & -.689 & $\mathrm{~L}$ & -.406 \\
\hline M & .035 & M & .094 & M & .225 & M & .090 \\
\hline
\end{tabular}

* Remarks: $\mathrm{FMC}=$ fuel moisture content (\%), $\log 10(\mathrm{EH})=$ effective humidity (\%), $\log 10(\mathrm{AI})=$ accumulation irradiation(lux), $\log 10(\mathrm{ED})=$ elapse day (day), $\mathrm{L}=$ loose, $\mathrm{M}=$ medium

Table 4. Predictive statistical models for fuel moisture

\begin{tabular}{lll}
\hline $\begin{array}{l}\text { Fallen leaves } \\
\text { layer }\end{array}$ & $\begin{array}{l}\mathrm{FMC}^{*}=1.169+0.272 * \log 10(\mathrm{EH})+0.08913 * \log 10(\mathrm{ALUX})-0.323 *(\mathrm{~L})- \\
0.127 *(\mathrm{M})-0.682 * \log 10(\mathrm{ED})\end{array}$ & $\left(\mathrm{R}^{2}=0.908\right)$ \\
\hline \multirow{2}{*}{ Humus layer } & $\begin{array}{l}\mathrm{FMC}=2.555-0.0064 * \log 10(\mathrm{EH})-0.205 * \log 10(\mathrm{ALUX})-0.034 *(\mathrm{~L})- \\
0.09 *(\mathrm{M})-0.301 * \log 10(\mathrm{ED})\end{array}$ & $\left(\mathrm{R}^{2}=0.804\right)$ \\
& & \\
$\begin{array}{l}\text { Soil layer } \\
(0 \sim 5 \mathrm{~cm})\end{array}$ & $\begin{array}{l}\mathrm{FMC}=2.082-0.155 * \log 10(\mathrm{EH})+0.01384 * \log 10(\mathrm{ALUX})-0.267 *(\mathrm{~L})- \\
\end{array}$ & $\left(\mathrm{R}^{2}=0.867\right)$ \\
$\begin{array}{l}0.048 *(\mathrm{M})-0.433 * \log 10(\mathrm{ED}) \\
(5 \sim 10 \mathrm{~cm})\end{array}$ & $\begin{array}{l}\mathrm{FMC}=1.604+0.00116 * \log 10(\mathrm{EH})+0.084 * \log 10(\mathrm{ALUX})-0.019 *(\mathrm{~L})- \\
\end{array}$ & \\
\hline
\end{tabular}

\section{Validation of the regression model}

We validated the fuel moisture prediction model against a set of independent daily measurements taken from April 1, 2009 for duration of 6 days after a precipitation event of $22.5 \mathrm{~mm}$ (Fig. 8, 9, 10, 11). The predicted moisture level of the fallen leaves layer was slightly overestimated on the first day, and then slightly underestimated from day 2 to 6 (Fig. 8). Predicted fuel moisture of the humus layer was consistently underestimated (Fig. 9). Predicted fuel moisture of the top soil level was slightly underestimated for the first day only, and for the remaining days the predictions well matched the observed values (Fig. 10). Predicted fuel moisture of the lower soil layer well matched the observed values throughout the prediction period (Fig. 11). We suspect

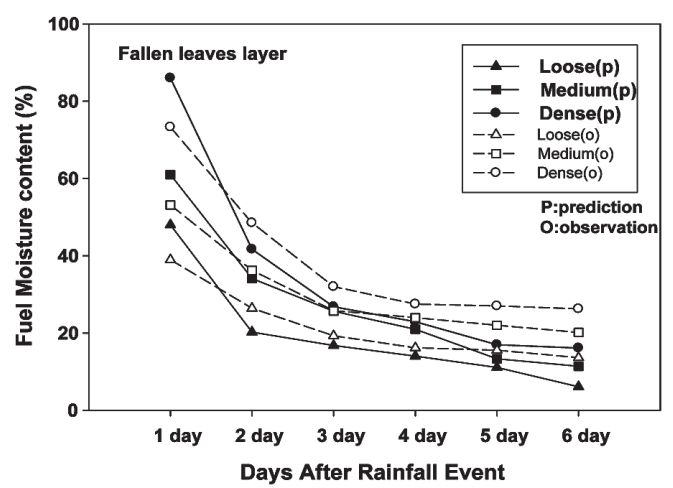

Fig. 8. Fuel moisture content changes of fallen leaves layer.

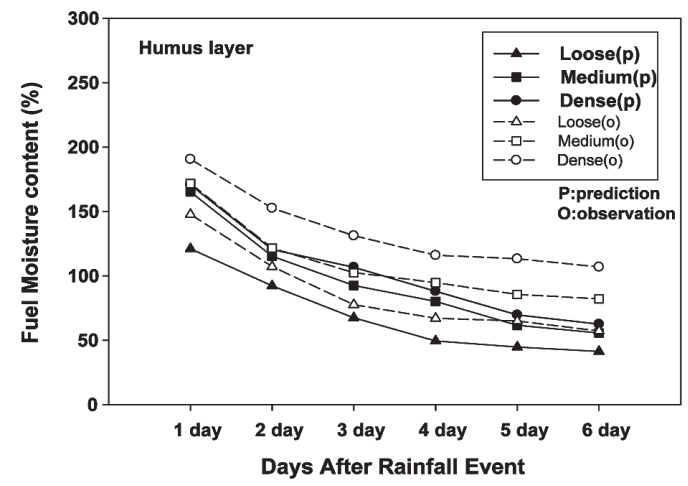

Fig. 9. Fuel moisture content changes of humus layer.

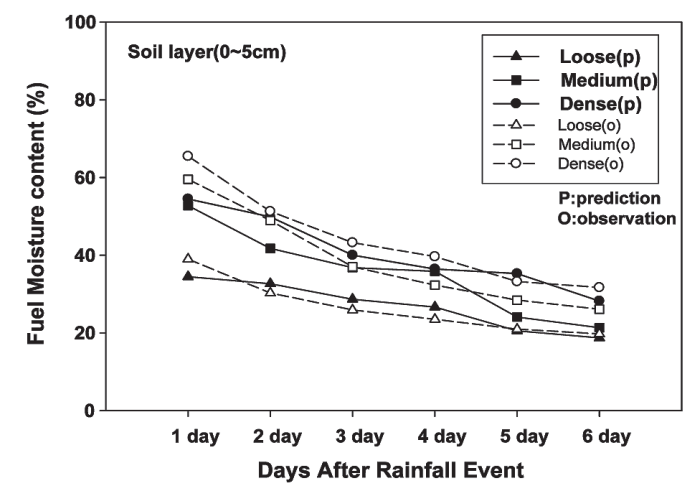

Fig. 10. Fuel moisture content changes of soil layer $(0 \sim 5 \mathrm{~cm})$ 


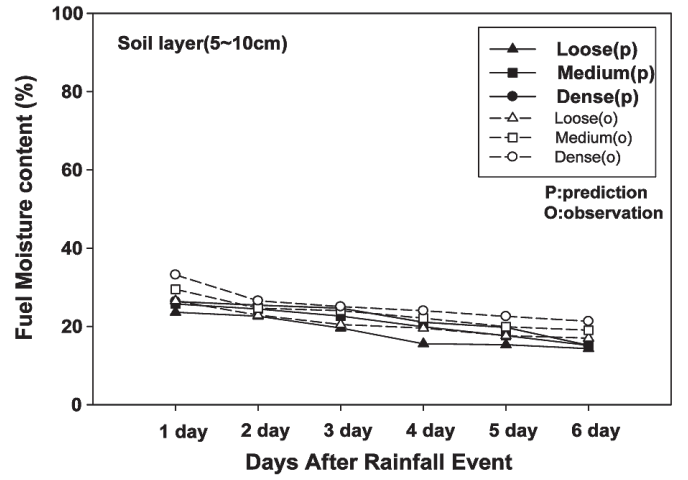

Fig. 11. Fuel moisture content changes of soil layer $(5 \sim 10 \mathrm{~cm})$.

that the departure between predicted and observed values resulted from the precipitation events preceding our sampling period.

\section{CONCLUSIONS}

This study investigated the changes in fuel moisture level among four different fuel layers on the forest floor fallen leaves, humus, top soil layer (0-5 cm depth), and lower soil layer $(5-10 \mathrm{~cm}$ depth). We selected stands with three stand density levels (low, medium, and high), and sampling continued for 6 days since the day of precipitation (precipitation $>5 \mathrm{~mm}$ ). Based on the measurements, we developed a regression model to predict changes in fuel moisture layers over time after rainfall.

1) Fuel moisture level of the fallen leaves layer at the high and medium density stands remained at 19-20\% after 6 days from the rainfall event. We propose that fire risk at such stands would decrease immediately after a significant rainfall event. However, at the low density stand, fuel moisture dropped to $17 \%$ on the third day, which is known to be low enough to cause higher fire risk. Our results also showed that the amount of accumulated fuel was an important factor for fire risk Fuel moisture changed slowly where there was greater amount of fuel accumulation.

2) The humus layer had the highest fuel moisture content among all fuel layers. Fuel moisture of the humus layer on the first day after rainfall was 147\%, 171\%, and $190 \%$ for low, medium, and high density stands, respectively. In addition, fuel moisture level of humus layer was less influenced by rainfall events. Our results suggest that rainfall mostly wets the surface fuel layer (fallen leaves), and fuel layers below humus layer may remain dry without a significant rainfall event. Therefore, presence of a thick humus layer may lead to a higher risk of re-ignition especially if such layer is already well-dried.

3) The fuel moisture of the top soil layer slightly decreased after rainfall, but the fuel moisture of the lower soil layer remained almost constant regardless of rainfall or stand density.

4) Our fuel moisture prediction model performed well in fitting the data $(\mathrm{r}$-square $=0.56-0.90, \mathrm{p}$-value $<$
0.001), and validated well against an independent data set.

\section{REFERENCES}

Anderson, H. E., R. D. Schuette, and R. W Mutch 1978 Time lag and equilibrium moisture content of ponderosa pine needles. United States Department of Agriculture, Forest Service, Research Paper INT-202: 28

Brown, J. K 1970 Physical fuel properties of ponderosa pine forest floors and cheargrass. United States Department of Agriculture, Forest Service, Research Paper INT-74: 16

Deeming, J. E., R. E. Burgan and J. D. Cohen 1977 The national fire-danger rating system-1978. United States Department of Agriculture, Forest Service, Research Paper INT-39: 1-63

East coast forest fire damaged area joint research group 2000 East coast forest fire area scrutiny report I: 15-26 (In Korean)

Fons, W. L 1946 Analysis of fire spread in light forest fuels. Journal of Agricultural Research, 72: 93-121

Fosberg, M. A 1977 Forecasting the 10-Hour Timelag Fuel Moisture. USDA For. Serv. Res. Pap. RM-187: 1-10

Forest Land Fire Research Group 1984 Revised Forest Land Fire guideline, Forest Fire Countermeasure Association: 146 (In Japanese)

Jung Y. H., S. Y. Lee, Y. C. Yeom, Y. H. Yeo 1989 Research on Estimating Forest Fire risk rates. Forestry Researcher Research report, 38: 117-123 (In Korean)

Kang, J. U., S. U. Kim, Y. C. Kim, J. K. Kim, J. S. Kim, S. C. Park, Y. G. Park, S. O. Lee, S. Y. Lee, O. S. Lee, C. H. Lee, H. H. Lee, S. B. Ju and J. H. Hyun 2002 Forest environment Conservation. Hyangmoonsa: 34-70 (In Korean)

Korea Forest Service 2010 Through statistical analysis of forest fire policy transition and countermeasures. Korea Forest Service: 198-243 (In Korean)

Kwon, C. G. 2009 A Study on the Forecast of Fuel Moisture Content's Changes in the Pinus Densiflora Forest after Rainfall. Kangwon National University: 26-42 (In Korean with English abstract)

Yamashita, K. 1983 Study on the Combustion of forest fire sparked. Japan National Research Institute of Fire and Disaster: 23-59 (In Japanese)

Lee S. Y. 1994 Research on Forest Fire occurrence risk rates and analyzing fire expanding factors, Dongguk University: 22-23 (In Korean with English abstract)

Lee S. Y., B. S. Lee, J. H. Lim 1997 Estimating Forest Fire occurrence risk rates using a humidity measurement rod. Forest Science collection of dissertations, 55: 150-157 (In Korean)

Lee, S. Y., C. G. Kwon, M. W. Lee, H. P. Lee and J. Y. Cha 2010 Development of Prediction Model of Fuel Moisture Changes in the Spring for the Pine Forest located the Yeongdong Region. (Focused on the Fallen Leaves and Soil Moisture Level) Journal of the Korea Institute of Fire Science \& Engineering, 24(2): 67-75 (In Korean with English abstract)

Pyne, S. J 1984 Introduction to Wildland Fire - Fire Management in the United States, John Wiley and Sons: 420

Song, C. G, Y, G. Baek and J. H. Park 2007 I analyzed the statistics spss. Hakjisa: 271-291 (In Korean)

Turner, J. A., Lawson, B. D 1978 Weather in the Canadian Forest Fire Danger Rating System. Pacific Forest Research Center. Victoria. B. C. BC-X-177: 40

Stock, B. J., M. E. Alexander, B. D. Lawson and C. E Van Wanger 1987 Canadian Forest Fire Danger Rating System. User' Guide: 4-11

Tanskanen, H., Venalainen, A. Puttonen, P. and A. Granstrom 2005 Impact of stand structure on surface fire ignition potential in Picea abies and Pinus sylvestris forest in southern Finland. Canadian Journal of Forest Research, 35: 410-420

Xanthopoulos, G. and R. H Wakimoto 1993 A time to ignition temperature-moisture relationship for branches of three western conifers. Canadian Journal of Forest Research, 23 $253-258$ 